\title{
(C) OPEN ACCESS \\ Expansion of disability across successive Mexican birth cohorts: a longitudinal modelling analysis of birth cohorts born 10 years apart
}

\author{
Collin F Payne, ${ }^{\oplus 1}$ Rebeca Wong ${ }^{2,3}$
}

\begin{abstract}
- Additional material is published online only. To view, please visit the journal online (http://dx.doi.org/10.1136/ jech-2019-212245)
\end{abstract}

${ }^{1}$ School of Demography, Australian National University, Canberra, Australian Capital Territory, Australia ${ }^{2}$ Department of Preventive Medicine and Community Health, The University of Texas Medical Branch, Galveston, Texas, USA

WHO/PAHO Collaborating Center on Aging and Health, Galveston, Texas, United States

Correspondence to Dr Collin F Payne, School of Demography, Australian National University, Canberra, ACT 0200, Australia; Collin.Payne@anu.edu.au

Received 6 February 2019 Revised 30 May 2019 Accepted 19 June 2019 Published Online First 20 July 2019

\begin{abstract}
Background Life expectancy (LE) in Mexico has risen rapidly since the 1950s. In high-income contexts, these increases have coincided with a compression of disability to later ages. However, little evidence on trends in disability-free LE (DFLE) exist from Mexico or elsewhere in Latin America.

Methods Using data from the Mexican Health and Aging Study, we compare changes in LE and DFLE in ages 50-59, 60-69 and 70-79 using birth-cohortspecific multistate lifetable models across successive 10 -year birth cohorts. Disability was measured using the Katz activities of daily living (ADL) index, and limitation was measured using a seven-item questionnaire on physical functioning.
\end{abstract}

Results Overall, Mexican adults born in 1953-1962 lived $0.87(p<0.001)$ fewer active years between ages 50 and 59 than individuals born in 1942-1951, a difference comprised of a 0.54-year $(p<0.001)$ increase in physically limited LE and a 0.27-year $(p<0.001)$ increase in ADL-disabled LE. Active LE declined by 1.13 $(p<0.001)$ years in ages 60-69, and by $0.93(p<0.001)$ years in ages 70-79, across successive 10-year birth cohorts. No substantial changes in total LE were seen in any age group, and the magnitude of the expansion of disability was larger in females than in males.

Conclusions Our results indicate that more recently born cohorts of Mexican adults are spending more years of life with physical limitations and disabilities. These results foreshadow a need to closely monitor adult health in middle-income contexts, as the epidemiological conditions under which disability has expanded in Mexico are similar to those seen in many other countries.

\section{INTRODUCTION}

The population of older adults in Mexico is one of the most rapidly growing in the world. ${ }^{1}$ Life expectancy (LE) has risen rapidly over the last half-century, and currently, stands at 79 years for females and 73 years for males, ${ }^{1}$ up from 50 and 47 years, respectively, in 1950. In Mexico, and throughout Latin America, population ageing is occurring at a much faster pace than economic development, resulting in severe restrictions on the pool of resources available to care for older adults. ${ }^{2}$ Providing care and support for this growing elderly population is one of the largest public health challenges facing Latin America today. ${ }^{3}$

Though the long-term trend in survival of older Mexicans shows marked improvements, a growing body of evidence finds a recent pattern of declining health and increasing chronic conditions among older adults. The prevalence of hypertension, diabetes and hypercholesterolaemia all increased markedly in prevalence among older individuals between 2000 and 2012, ${ }^{4}$ and diabetes prevalence among those aged $60+$ years has continued to rise. ${ }^{5}$ Rising trends in obesity have been implicated in a substantial burden of excess mortality among the population aged $60+$ years $^{6}$ and are projected to have negative effects on future trends in LE. ${ }^{7}$ Rates of dementia incidence are high in Mexico compared with higher-income populations, ${ }^{8}$ and dementia cases are set to rise rapidly across Latin America in the coming decades due to demographic and health transitions. ${ }^{9}$ Gains in LE have also stagnated in Mexico, in recent years, due to persistently high rates of interpersonal violence and a rapid increase in obesity and diabetes mellitus. ${ }^{10-13}$

In the classical epidemiological transition, expansion in LE was thought to result in a compression of disability to a smaller portion of late life, with medical advances and improved health behaviours increasing the age of onset of morbidity or disability more quickly than rises in LE. ${ }^{14}$ Evidence suggests that this compression is broadly occurring in many high-income contexts, ${ }^{15-18}$ though evidence is mixed in the USA, particularly at late-middle ages. ${ }^{19-21}$ A different theoretical viewpoint, predicting an expansion of disability or morbidity, has also been put forward. ${ }^{22}$ This theory posits that reductions in early-life mortality may lead individuals with worse health to survive longer than they would have in the past. This second viewpoint needs consideration in the case of Mexico. Prior research on Latin America has found that over half of the post-1945 mortality decline was associated directly with the adoption of medical technologies that reduced infant and child mortality (eg, antibiotics, vaccination and pesticides for malaria control), as opposed to resulting from broad social and economic development. ${ }^{23}$ This legacy of improved survivorship, but slow development, may lead to successive cohorts at higher risk of morbidity and disability in Latin America, as the delayed effects of poor childhood conditions have a lasting imprint on underlying health. ${ }^{24-26}$ Indeed, the continued effects of these poor early-life conditions may in part be behind the rapid rises in cardiovascular disease, obesity and diabetes observed in the region. ${ }^{27} 28$

In this paper, we use data from the Mexican Health and Aging Study (MHAS), a long-running longitudinal sample survey of older adults in 
Mexico, ${ }^{29}$ to examine whether successive birth cohorts in the Mexican population are living more of their life with physical limitations and/or disability. Our analyses focus on measuring disability-free LE (DFLE) across birth cohorts in the Mexican population. DFLE distinguishes between years that are free of limitations and years with activity limitations or disability, providing a metric that combines mortality and disability into a single measure. We compare cohort changes in disability and longevity using data from two distinct periods (2001-2003 and 2012-2015) to understand whether the Mexican population is experiencing a compression or expansion of disability.

\section{METHODS}

\section{Study participants}

Data came from the MHAS. ${ }^{29}$ MHAS is a Health and Retirement Study, sister study of adults aged $50+$ years, with waves of data in 2001, 2003, 2012 and 2015. Our analyses use individuals who were interviewed in both 2001 and 2003 or who died between waves ( $\mathrm{N}=14$ 250, response rate 93\%), and individuals who were interviewed in both 2012 and 2015 or who died between waves $(\mathrm{N}=15168$, response rate $88 \%)$. A refresher sample of 6259 new individuals (primarily aged 50-59) was added in 2012.

\section{Measures}

We conceptualise disability within the framework of the disablement process, ${ }^{30}$ with disability defined as a gap between an individual's capacities and the demands of a given activity. Individuals are classified as physically limited if they report difficulty on one or more of the following seven physical activities: walking a block, sitting for 2 hours, getting up from a chair, climbing a flight of stairs, kneeling or crouching, pushing or pulling a heavy object, or carrying heavy $(5 \mathrm{~kg})$ objects. Individuals are classified as activities of daily living (ADL) disabled if they report difficulty or inability to do any of the following five activities: bathing, eating, getting in/out of bed, toileting and walking across a room. ${ }^{31}$ Where necessary, proxy responses on ADL disability are used. Proxy respondents were not asked the physical activity questions; individuals requiring the assistance of a proxy for health reasons were assumed to be physically limited if the proxy did not report an ADL disability. Individuals who report both physical limitations and ADL disabilities are classified as ADL disabled. Individuals who reported no physical limitations or ADL disabilities are classified as active.

\section{Statistical analyses}

Prior research on population-level disability in low-income and middle-income countries has relied largely on period comparisons-that is, measuring mortality and disability conditions in a population at different points in time, and observing changes in the trends over time. However, tracking disability using only period estimates may obscure substantial heterogeneity in trends between birth cohorts, and provides limited information on how trends in DFLE have shifted over time and across cohorts. Measuring cohort changes in disability provides results that match more closely with the lived experience of individuals in a population, ${ }^{32}$ and prior work has found relatively poor correspondence between measures of period and cohort DFLE. ${ }^{33}$

Our analyses compare LE and DFLE across successive 10-year birth cohorts in three bounded 10-year age ranges-ages 50-59, 60-69 and 70-79. These estimates are also known as 'partial' or 'temporary' LE. Online supplemental figure 1 displays a Lexis diagram showing this comparison graphically for estimating
DFLE in ages 50-59 for those born in 1942-1951 (who were aged 50-59 in the 2001 MHAS) and those born in 1953-1962 (the new sample of 50-59 year-olds added in the 2012 MHAS). We model the conditional annual probability of experiencing a transition between the four modelled states (active, physically limited, ADL disabled and deceased) as a function of age and gender, separately by birth cohort and observation period (20012003 and 2012-2015, outlined in the dark dashed line), using a cumulative logistic regression model with a relaxed proportional odds assumption on gender, ${ }^{34}$ and stratified by initial health state. Transitions between health states are assumed to occur at a random time between observations. Transition probability estimates were obtained using PROC SURVEYLOGISTIC in SAS V.9.4. In all analyses, in this paper, the cohorts are distinct-that is, there are no individuals contributing person-years of observation to the two different cohorts compared in each age-range.

These observed transition probabilities are then used as the input for a microsimulation-based multistate life table model. ${ }^{35-37}$ To calculate LE and DFLE, we create synthetic cohorts of 100 000 individuals with the same initial gender and health state distribution as the study population in a given age-range and cohort. We then 'age' these individuals forward year by year via microsimulation, applying the age-specific and gender-specific mortality rates and probabilities of transitioning in and out of disability estimated from the data. This process is then repeated until the end of the age-range under study - that is, when investigating DFLE for a given cohort in ages 50-59, the model will microsimulate the life-courses of 100000 individuals starting at age 50 and ending at exact age 60 . The resulting synthetic cohort is analysed to estimate active, limited, ADL disabled and total LE. Point estimates shown are from transition probabilities estimated from the full sample. CIs, which reflect both the uncertainty of the estimated parameters and the uncertainty from the microsimulation, were created by re-estimating the above analysis sequence using 499 bootstrap re-samples from each birth cohort under study. We took the central $95 \%$ of the distribution of these bootstrapped parameters as our $95 \% \mathrm{CI}$, and calculated non-parametric $\mathrm{p}$ values for differences in means between birth cohorts. ${ }^{38}$ We include inverse-probability (IP) weights to correct for potential bias introduced from differential loss to follow-up. The weight generating model includes all sociodemographic and health variables included in online supplementary table 1 and the cross-sectional survey sampling weight. ${ }^{39}$ IP weights were generated separately for each age group and cohort included in these analyses.

\section{RESULTS}

Online supplementary table 1 presents the sociodemographic and health characteristics of the MHAS population at the two baseline waves for this analysis-2001 and 2012. Across all age groups, the prevalence of physical limitations and ADL disability are higher in 2012 than in 2001. Self-reported diabetes is more prevalent in 2012 compared with 2001, as is hypertension and obesity. The age-specific 2012 populations are more likely to have received some formal education, less likely to report ever having smoked and more likely to have visited a physician in the past 12 months. Across nearly all ADL items, prevalence is higher in the 2012 wave than the 2001 wave. Childhood socioeconomic conditions (measured by the presence of household toilet facilities before age 10 years ${ }^{40}$ ) show slight improvements over successive cohorts of 60-69 and 70-79 year-olds, while the proportion reporting a serious childhood illness remained stable. Cognitive status, as measured by the Cross-Cultural 
Cognitive Examination test, ${ }^{8}{ }^{41}$ suggests that successive cohorts were substantially more likely to have normal cognitive status and less likely to be cognitively impaired.

\section{Age 50-59}

The top panel of table 1 and the top panels of figures 1-3 compare partial LE and DFLE in ages 50-59 between two 10-year cohorts: those born between 1942 and 1951 (observed in the period 2001-2003), and those born between 1953 and 1962 (the refresher sample added to the third MHAS wave; observed in the period 2012-2015). Overall, individuals born in 1953-1962 lived $0.87(\mathrm{p}<0.001)$ fewer active years between ages 50 and 59 than individuals born in 1942-1951, a difference comprised of a 0.54 -year $(\mathrm{p}<0.001)$ increase in limited LE and a 0.27 -year $(\mathrm{p}<0.001)$ increase in ADL-disabled LE. Active LE for women declined from $56 \%$ to $44 \%$ as a proportion of partial LE (figure 3), and LE spent physically limited rose from 39\% to $48 \%$. Partial female LE between ages 50 and 59 also appears to have declined slightly $(-0.15$ years, $p=0.026)$. In contrast to women, men did not experience a proportionate expansion of disability in ages 50-59 (figure 2), though LE with an ADL disability increased by $0.15(\mathrm{p}=0.012)$ years. Online supplementary table 2 provides partial LE and DFLE estimates in ages 50-59 separately by initial disability state.

\section{Age 60-69}

The middle panel of table 1 and the middle panels of figures 1-3 compare partial DFLE in ages 60-69 across the 1932-1941 and 1943-1952 birth cohorts. In the overall sample, active LE declined by 1.13 years $(\mathrm{p}<0.001)$ across the two birth cohorts, comprised of a 0.59 -year increase $(p<0.001)$ in limited LE and a 0.53 -year increase $(p<0.001)$ in ADL-disabled LE. We find no evidence that total partial LE between ages 60 and 69 has changed between these two cohorts. Active LE for women declined by 1.34 years $(p<0.001)$, compared with a 0.82 -year $(p<0.001)$ decline for men. The proportion of women's partial LE spent active in these ages declined from $47 \%$ to $32 \%$ between the two birth cohorts (figure 3), and declined from $61 \%$ to $53 \%$ for men (figure 2). Online supplementary table 3 provides partial LE and DFLE estimates in ages 60-69 separately by initial disability state.

\section{Age 70-79}

The bottom panel of table 1 and the bottom panels of figures 1-3 compare partial LE and DFLE in ages 70-79 between the 19221931 and 1933-1943 birth cohorts. Total partial LE between ages 70 and 79 is similar between the two cohorts, though active LE declined by 0.93 years $(p<0.001)$. The proportion of partial LE spent active in these ages declined from $43 \%$ to $32 \%$ in the full sample (figure 1). In the more recently born cohort, women expect to spend less than a quarter of these years with no physical limitations (figure 3), and men expect to spend less than half of these years active (figure 2). Men show about a half-year rise in limited LE and a slightly smaller increase in disabled LE between ages 70 and 79 across these two cohorts, and most of the decline in active LE for women is explained by a 0.70 -year $(p<0.001)$ increase in ADL-disabled LE. Online supplementary table 4 provides partial LE and DFLE estimates in ages 70-79 separately by initial disability state.

\section{DISCUSSION}

This paper focuses on measuring recent trends in population-level physical health and disability in Mexico. We utilise
Table 1 Total, active, limited and ADL-disabled life expectancy in ages $50-59,60-69$ and $70-79$

\begin{tabular}{|c|c|c|c|c|}
\hline \multicolumn{5}{|c|}{ Age 50-59 } \\
\hline \multicolumn{5}{|c|}{ Birth cohort } \\
\hline & 1942-1951 & 1953-1962 & Diff & $P$ value of diff \\
\hline \multicolumn{5}{|l|}{ Overall } \\
\hline Total & 9.67 (9.60 to 9.72 ) & 9.60 (9.53 to 9.68$)$ & -0.07 & 0.128 \\
\hline Active & 5.90 (5.70 to 6.06$)$ & 5.03 (4.73 to 5.32$)$ & -0.87 & $<0.001$ \\
\hline Limited & 3.38 (3.24 to 3.57 ) & 3.92 (3.67 to 4.19$)$ & 0.54 & $<0.001$ \\
\hline ADL disabled & $0.39(0.32$ to 0.45$)$ & $0.66(0.53$ to 0.79$)$ & 0.27 & $<0.001$ \\
\hline \multicolumn{5}{|l|}{ Men } \\
\hline Total & 9.64 (9.51 to 9.72 ) & 9.69 (9.56 to 9.80$)$ & 0.05 & 0.210 \\
\hline Active & 6.46 (6.15 to 6.65$)$ & 6.35 (5.88 to 6.70$)$ & -0.11 & 0.616 \\
\hline Limited & 2.84 (2.66 to 3.10 ) & 2.85 (2.53 to 3.21$)$ & 0.01 & 0.960 \\
\hline ADL disabled & 0.34 (0.25 to 0.43$)$ & 0.49 (0.37 to 0.66$)$ & 0.15 & 0.012 \\
\hline \multicolumn{5}{|l|}{ Women } \\
\hline Total & 9.70 (9.62 to 9.78 ) & 9.55 (9.46 to 9.65$)$ & -0.15 & 0.026 \\
\hline Active & 5.43 (5.19 to 5.69$)$ & 4.21 (3.92 to 4.56$)$ & -1.22 & $<0.001$ \\
\hline Limited & 3.83 (3.63 to 4.07 ) & 4.58 (4.29 to 4.88$)$ & 0.75 & $<0.001$ \\
\hline ADL disabled & 0.44 (0.35 to 0.51$)$ & 0.76 (0.59 to 0.93$)$ & 0.32 & $<0.001$ \\
\hline \multicolumn{5}{|c|}{ Age $60-69$} \\
\hline \multicolumn{5}{|c|}{ Birth cohort } \\
\hline & 1932-1941 & 1943-1952 & Diff & $P$ value of diff \\
\hline \multicolumn{5}{|l|}{ Overall } \\
\hline Total & 9.15 (9.02 to 9.26$)$ & 9.13 (9.04 to 9.23$)$ & -0.02 & 0.772 \\
\hline Active & 4.91 (4.72 to 5.12 ) & 3.78 (3.54 to 3.99$)$ & -1.13 & $<0.001$ \\
\hline Limited & 3.67 (3.49 to 3.84$)$ & 4.26 (4.07 to 4.46$)$ & 0.59 & $<0.001$ \\
\hline ADL disabled & 0.57 (0.48 to 0.65$)$ & 1.10 (0.97 to 1.23$)$ & 0.53 & $<0.001$ \\
\hline \multicolumn{5}{|l|}{ Men } \\
\hline Total & 9.12 (8.94 to 9.29 ) & 9.05 (8.91 to 9.20 ) & -0.07 & 0.486 \\
\hline Active & 5.61 (5.32 to 5.89 ) & 4.79 (4.45 to 5.10$)$ & -0.82 & $<0.001$ \\
\hline Limited & 3.12 (2.87 to 3.37 ) & 3.42 (3.20 to 3.68$)$ & 0.30 & 0.002 \\
\hline ADL disabled & 0.40 (0.31 to 0.51$)$ & 0.85 (0.70 to 0.97$)$ & 0.45 & $<0.001$ \\
\hline \multicolumn{5}{|l|}{ Women } \\
\hline Total & 9.17 (9.03 to 9.33$)$ & 9.19 (9.07 to 9.29$)$ & 0.02 & 0.806 \\
\hline Active & 4.29 (4.04 to 4.58$)$ & 2.95 (2.69 to 3.20 ) & -1.34 & $<0.001$ \\
\hline Limited & 4.17 (3.93 to 4.38 ) & 4.94 (4.67 to 5.17$)$ & 0.77 & $<0.001$ \\
\hline ADL disabled & 0.71 (0.59 to 0.84$)$ & 1.30 (1.16 to 1.49$)$ & 0.59 & $<0.001$ \\
\hline \multicolumn{5}{|c|}{ Age 70-79 } \\
\hline \multicolumn{5}{|c|}{ Birth cohort } \\
\hline & 1922-1931 & 1933-1942 & Diff & $P$ value of diff \\
\hline \multicolumn{5}{|l|}{ Overall } \\
\hline Total & 8.43 (8.24 to 8.65$)$ & 8.50 (8.35 to 8.62$)$ & 0.07 & 0.578 \\
\hline Active & 3.66 (3.38 to 3.95$)$ & 2.73 (2.45 to 2.90$)$ & -0.93 & $<0.001$ \\
\hline Limited & 3.70 (3.47 to 3.95$)$ & 4.13 (3.91 to 4.36$)$ & 0.43 & $<0.001$ \\
\hline ADL disabled & 1.07 (0.91 to 1.22$)$ & 1.64 (1.50 to 1.84$)$ & 0.57 & $<0.001$ \\
\hline \multicolumn{5}{|l|}{ Men } \\
\hline Total & 8.39 (8.09 to 8.69$)$ & 8.44 (8.22 to 8.62 ) & 0.05 & 0.782 \\
\hline Active & 4.40 (4.02 to 4.82$)$ & 3.52 (3.16 to 3.77 ) & -0.88 & $<0.001$ \\
\hline Limited & 3.14 (2.83 to 3.46$)$ & 3.67 (3.38 to 3.96$)$ & 0.53 & $<0.001$ \\
\hline ADL disabled & 0.85 (0.68 to 1.02 ) & 1.25 (1.06 to 1.43$)$ & 0.40 & $<0.001$ \\
\hline \multicolumn{5}{|l|}{ Women } \\
\hline Total & 8.48 (8.21 to 8.74$)$ & 8.55 (8.37 to 8.70$)$ & 0.07 & 0.650 \\
\hline Active & 2.95 (2.59 to 3.27$)$ & 2.05 (1.74 to 2.23$)$ & -0.90 & $<0.001$ \\
\hline Limited & 4.24 (3.92 to 4.65$)$ & 4.53 (4.24 to 4.84 ) & 0.29 & 0.120 \\
\hline ADL disabled & $1.28(1.04$ to 1.54$)$ & 1.98 (1.79 to 2.28$)$ & 0.70 & $<0.001$ \\
\hline
\end{tabular}

Data are life expectancy in years unless specified, with the $95 \% \mathrm{Cl}$ in brackets after point estimate. Models adjusted for age and sex (only for overall).

ADL, activities of daily living; Diff, difference. 


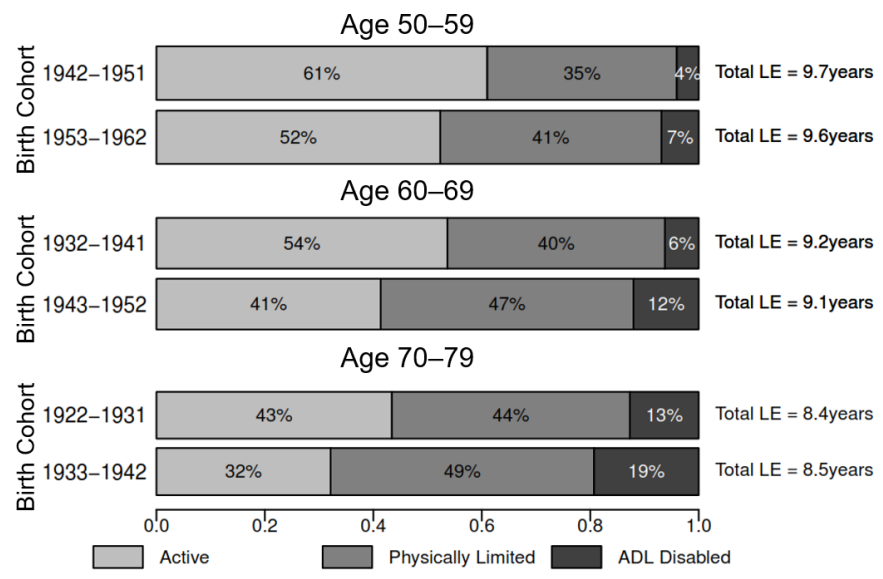

Figure 1 Proportion of remaining LE in active, limited and ADLdisabled life, ages 50-59, 60-69 and 70-79, both sexes combined. The height and area of each bar are proportional to the overall LE in ages 50-59, 60-69 and 70-79, and the differently shaded areas represent the distribution of the LE across disability-free, physically limited and ADL-disabled life. The bars do not necessarily reflect the ordering of these life-years by disability states, as individuals in our analysis can recover and relapse between disability states, so not all years of disability are spent at the end of life. ADL, activities of daily living; $L E$, life expectancy.

data from MHAS to investigate how the disability burden of successive cohorts of older adults in Mexico has changed and to determine whether a compression of disability is occurring in Mexico. We, instead, find evidence for a trend of increasing physical limitation and disablement among successive cohorts of older Mexican adults. Across all age groups, more recently born cohorts lived more years with physical limitations and disabilities, with women, in particular, experiencing substantial reductions in active LE across older adult ages.

Our results need to be understood in the context of the larger macroeconomic trends and policy changes occurring during

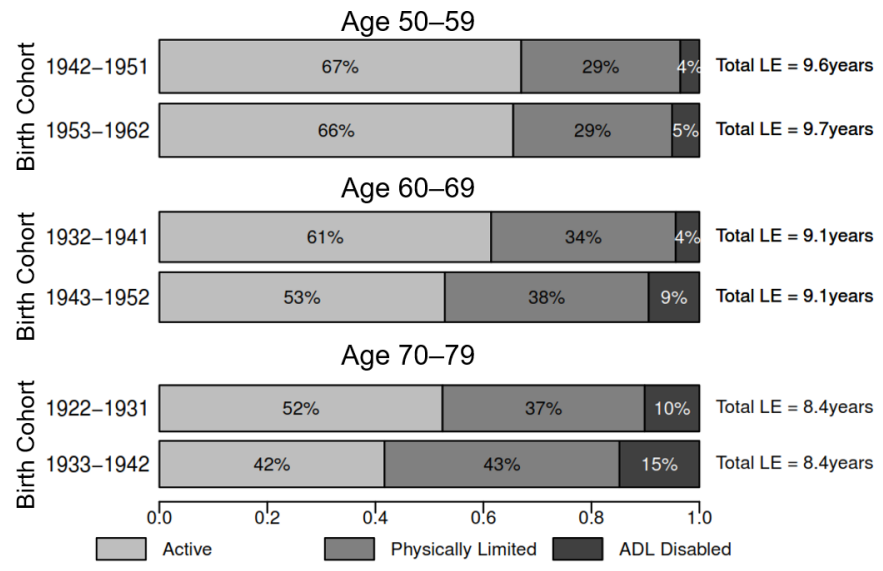

Figure 2 Proportion of remaining LE in active, limited and ADLdisabled life, ages 50-59, 60-69 and 70-79, men. The height and area of each bar are proportional to the overall LE in ages 50-59, 60-69 and $70-79$, and the differently shaded areas represent the distribution of the LE across disability-free, physically limited and ADL-disabled life. The bars do not necessarily reflect the ordering of these life-years by disability states, as individuals in our analysis can recover and relapse between disability states, so not all years of disability are spent at the end of life. $A D L$, activities of daily living; $L E$, life expectancy.

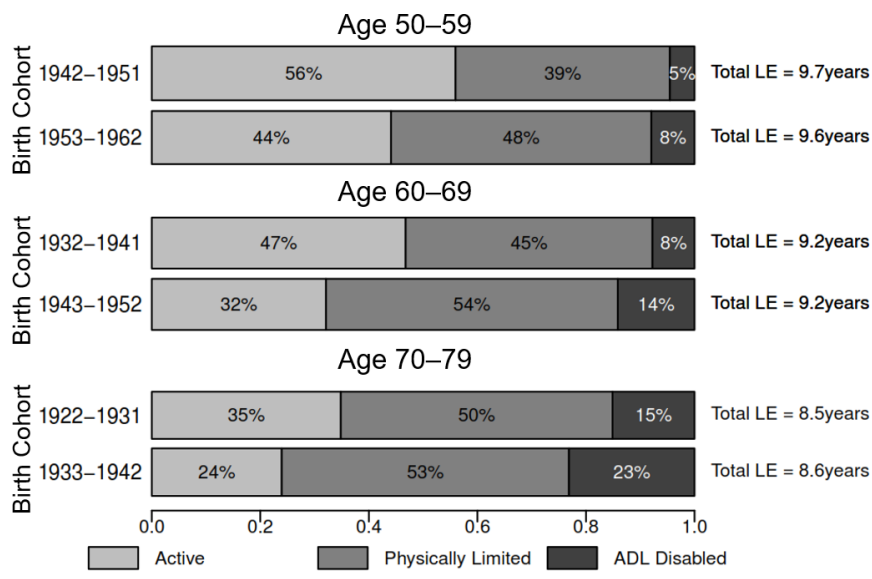

Figure 3 Proportion of remaining LE in active, limited and ADLdisabled life, ages 50-59, 60-69 and 70-79, women. The height and area of each bar are proportional to the overall LE in ages 50-59, 60-69 and $70-79$, and the differently shaded areas represent the distribution of the LE across disability-free, physically limited and ADL-disabled life. The bars do not necessarily reflect the ordering of these life-years by disability states, as individuals in our analysis can recover and relapse between disability states, so not all years of disability are spent at the end of life. $A D L$, activities of daily living; $L E$, life expectancy.

the period covered in our analyses (2001-2015). This period spanned the introduction of a major social programme designed to improve health and well-being in Mexico: Seguro Popular, a publicly funded health insurance scheme designed to target Mexico's large population of uninsured individuals. Seguro Popular had been in existence on a smaller scale since 2003, but coverage gradually expanded to all states during the study period, and by 2012 , reached almost complete coverage. ${ }^{42}$ The introduction of Seguro Popular increased access to and utilisation of diagnostic tests among the older adult population, but evidence on the programme's effectiveness for improving treatment of non-communicable diseases is weaker. ${ }^{43}$ However, there is the possibility that our results could reflect Seguro Popular's success in increasing survival for individuals in poor health.

Though the policy environment appeared conducive for improvements in population health during the study period, broader social/economic trends were working in the opposite direction. Mexico was hard hit by the 2008 financial crisis, with GDP dropping by $7 \%$ in 2009. Drug violence escalated in many regions of Mexico during this time period, and though rates of direct mortality due to violence were low among the older adult population in our study, this spike in drug-related violence led to a decline in foreign investment and tourism income. ${ }^{44}$ These trends had an outsized effect on older adults, as the undiversified income sources and investments of older adults in Mexico led older individuals to rely heavily on family for financial stability. ${ }^{45}$

In conjunction with the rising trends in diabetes, obesity and other chronic non-communicable diseases, ${ }^{4} 54647$ Mexico has also experienced a rapid increase in survivorship to old ages. Online supplementary figure 2 shows the proportion of each birth cohort that survived to ages 50,60 and 70, by gender, based on data from the LaMDa database. ${ }^{48}$ From the 1940 to 1960 birth cohorts, the proportion of newborns surviving to age 50 rose from just over $50 \%$ for men (60\% for women) to $73 \%$ for men ( $80 \%$ for women). Similar rapid increases in survivorship to ages 60 and 70 are seen across successive birth cohorts. Assuming that mortality is related to frailty (ie, an individual-level latent trait comprising 'health'), cohorts with higher 
mortality selection into older ages (where fewer cohort members have reached older ages) will be overall less frail, and thus experience fewer disabling conditions. ${ }^{49}$ Previous theoretical work focusing on Latin America ${ }^{24}$ has suggested that these changes in survivorship would lead to successive cohorts at higher risk of disability and chronic disease, and our findings seem to support these conclusions. Our findings suggest that these rapid declines in the level of mortality selection into older ages, combined with secular changes in cardiovascular/cardiometabolic diseases and economic conditions, are driving the expansion in limited and disabled LE seen in Mexico.

\section{Limitations and strengths}

In evaluating our results, several limitations need to be considered. The time between interviews varied, with a 2 -year period between the 2001 and 2003 waves and a 3-year period between the 2012 and 2015 waves. This difference in time periods may lead us to miss proportionately more short-term transitions in the 2012-2015 period, lowering the predicted transition rates of both onset of limitation/disability and recovery from limitation/disability. On the basis of prior empirical and simulation studies, these downward biases are in large part offsetting, and the 1-year difference in observation periods should still produce unbiased LE and DFLE estimates. ${ }^{3650}$ Individuals who experience a health transition between waves of data collection are assumed to experience only a single transition during the period between surveys, which likely misses shorter-term transitions between health statuses. Measurement of health conditions, such as diabetes, obesity and hypertension, was not available in the 2001 or 2003 waves of MHAS, limiting our ability to explore the role of specific conditions in driving our results.

One of the main strengths of these analyses is the focus on understanding disability change across successive birth cohorts. With a few notable exceptions, ${ }^{21} 3651$ most work investigating the compression has relied on measuring mortality and disability conditions in a population at different points in time, using data aggregated across many cohorts in a population. Though this approach may be useful for monitoring aggregate trends in population-level disability, these results do not easily translate to the experience of any given cohort of individuals. Disability and mortality are strongly linked to cohort-specific life-course exposures, but period-based models obscure the substantial heterogeneity between birth cohorts. ${ }^{32}$ Our results centre on measuring how partial total and disability-free LE are changing within age groups over successive birth cohorts, a metric more directly applicable to understanding trends in population health.

\section{CONCLUSION}

In Mexico, increasing trends in LE have not led to a compression of disability. This expansion of disability coincided with a rapid rise in obesity, cardiovascular and cardiometabolic conditions in Mexico, and substantial changes in early-life mortality selection and survivorship to older ages. As our analyses were observational in nature, we are unable to determine the relative importance of these overlapping trends. However, the context in which disability expanded in Mexico is by no means uniquemany other countries in Latin America, and indeed in many other middle-income contexts worldwide, have seen broadly similar epidemiological and demographic changes in recent decades. Where similar data exists, the methods developed in these analyses could be used to elucidate trends in health over time and across birth cohorts. These results foreshadow a need to more closely monitor cohort trends in adult health across middle-income contexts to understand whether similar expansions of disability are occurring in other countries.

\section{What is already known on this subject}

- Increases in life expectancy have gone along with a compression of disability in high-income contexts, but whether this is happening in low-income and middleincome contexts is unknown. Prior theoretical research on Latin America posits the delayed effects of poor childhood conditions, but increasing survivorship to older ages, may lead to successive cohorts at higher risk of morbidity and disability in Latin America.

\section{What this study adds}

- Instead of successive generations living longer and with less disability, we found increasing physical limitation and disablement among successive cohorts of older Mexican adults. This expansion of disability overlapped with a rapid rise in obesity, cardiovascular and cardiometabolic conditions in Mexico, and substantial changes in early-life mortality selection and survivorship to older ages. The epidemiological conditions under which disability has expanded in Mexico are similar to those in many other countries in Latin America.

Acknowledgements The authors would like to thank the MHAS study team and participants.

Contributors CFP conceived the study, analysed the data and drafted the manuscript. RW designed the MHAS study and oversaw the collection of data. All the authors interpreted the data, critically revised the manuscript and approved the final version. All the authors agree to be accountable for all aspects of the work.

Funding The MHAS is partly sponsored by the National Institutes of Health/ National Institute on Aging, grant number R01AG018016 in the USA and the National Institute of Statistics and Geography (INEGI) in Mexico. CFP acknowledges additional support from the ANU Futures Scheme.

Competing interests None declared.

\section{Patient consent for publication Not required.}

Ethics approval Ethics committee approvals for the MHAS were obtained from the University of Texas-Medical Branch and the INEGI in Mexico. No specific ethical approval was needed for this work.

Provenance and peer review Not commissioned; externally peer reviewed.

Data availability statement Data are available in a public, open access repository.

Open access This is an open access article distributed in accordance with the Creative Commons Attribution Non Commercial (CC BY-NC 4.0) license, which permits others to distribute, remix, adapt, build upon this work non-commercially, and license their derivative works on different terms, provided the original work is properly cited, appropriate credit is given, any changes made indicated, and the use is non-commercial. See: http://creativecommons.org/licenses/by-nc/4.0/.

\section{REFERENCES}

1 US Census Bureau. US Census International Data Base (2016), 2016. Available: http:// www.census.gov/data/developers/data-sets/international-database.html [Accessed 18 Sep 2016].

2 Cotlear D, ed. Population Aging: Is Latin America Ready? Washington, DC: World Bank Publications, 2010.

3 National Academies of Sciences E. Strengthening the Scientific Foundation for Policymaking to Meet the Challenges of Aging in Latin America and the Caribbean: Summary of a Workshop, 2015. Available: https://www.nap.edu/catalog/21800/ strengthening-the-scientific-foundation-for-policymaking-to-meet-the-challenges-ofaging-in-latin-america-and-the-caribbean [Accessed 1 Aug 2018].

4 Manrique-Espinoza B, Salinas-Rodríguez A, Moreno-Tamayo KM. Condiciones de salud y estado funcional de los adultos mayores en México. Salud Pública de México 2013;55:323-31. 
5 Rojas-Martínez R, Basto-Abreu A, Aguilar-Salinas CA, et al. Prevalencia de diabetes por diagnóstico médico previo en México. Salud Pública de México 2018;60:224-32.

6 Monteverde M, Noronha K, Palloni A, et al. Obesity and excess mortality among the elderly in the United States and Mexico. Demography 2010;47:79-96.

7 Palloni A, Beltrán-Sánchez H, Novak B, et al. Adult obesity, disease and longevity in Mexico. Salud Publica Mex 2015;57:22-30.

8 Mejia-Arango S, Gutierrez LM. Prevalence and incidence rates of dementia and cognitive impairment no dementia in the Mexican population: data from the Mexican Health and Aging Study. J Aging Health 2011;23:1050-74.

9 Custodio N, Wheelock A, Thumala D, et al. Dementia in Latin America: Epidemiological Evidence and Implications for Public Policy. Front Aging Neurosci 2017;9.

10 Aburto JM, Beltrán-Sánchez H. Upsurge of Homicides and Its Impact on Life Expectancy and Life Span Inequality in Mexico, 2005-2015. Am J Public Health 2019;109:483-9.

11 Canudas-Romo V, García-Guerrero VM, Echarri-Cánovas CJ. The stagnation of the Mexican male life expectancy in the first decade of the 21st century: the impact of homicides and diabetes mellitus. J Epidemiol Community Health 2015;69:28-34.

12 Canudas-Romo V, Aburto JM, García-Guerrero VM, et al. Mexico's epidemic of violence and its public health significance on average length of life. J Epidemiol Community Health 2017;71:188-93.

13 Aburto JM, Beltrán-Sánchez H, García-Guerrero VM, et al. Homicides In Mexico Reversed Life Expectancy Gains For Men And Slowed Them For Women, 2000-10. Health Aff 2016;35:88-95.

14 Fries JF. Aging, natural death, and the compression of morbidity. N Engl J Med 1980;303:130-5.

15 Cutler DM, Ghosh K, Landrum MB. U Evidence for Significant Compression of Morbidity In the Elderly U.S. Population National Bureau of Economic Research; 2013. http://www.nber.org/papers/w19268

16 Christensen K, Thinggaard M, Oksuzyan A, et al. Physical and cognitive functioning of people older than 90 years: a comparison of two Danish cohorts born 10 years apart. Lancet 2013;382:1507-13.

17 Sundberg L, Agahi N, Fritzell J, et al. Trends in health expectancies among the oldest old in Sweden, 1992-2011. Eur J Public Health 2016;26:1069-74.

18 Kreft D, Doblhammer G. Expansion or compression of long-term care in Germany between 2001 and 2009? A small-area decomposition study based on administrative health data. Popul Health Metr 2016;14:24.

19 Crimmins EM, Beltran-Sanchez H. Mortality and Morbidity Trends: Is There Compression of Morbidity? J Gerontol B Psychol Sci Soc Sci 2011;66B:75-86.

20 Martin LG, Freedman VA, Schoeni RF, et al. Trends In Disability And Related Chronic Conditions Among People Ages Fifty To Sixty-Four. Health Aff 2010;29:725-31.

21 Beltrán-Sánchez H, Jiménez MP, Subramanian SV. Assessing morbidity compression in two cohorts from the Health and Retirement Study. J Epidemiol Community Health 2016;70:1011-6.

22 Gruenberg EM. The failures of success. Milbank Mem Fund Q Health Soc 1977;55:3-24.

23 Palloni A, Wyrick R. Mortality decline in Latin America: changes in the structure of causes of deaths, 1950-1975. Soc Biol 1981;28:187-216.

24 Palloni A, Souza L. The fragility of the future and the tug of the past: Longevity in Latin America and the Caribbean. Demogr Res 2013;29:543-78.

25 Palloni A, McEniry M. Aging and health status of elderly in Latin America and the Caribbean: preliminary findings. J Cross Cult Gerontol 2007;22:263-85.

26 Monteverde M, Noronha K, Palloni A. Effect of early conditions on disability among the elderly in Latin America and the Caribbean. Popul Stud 2009;63:21-35.

27 Smith CJ, Ryckman KK. Epigenetic and developmental influences on the risk of obesity, diabetes, and metabolic syndrome. Diabetes Metab Syndr Obes 2015;8:295-302.

28 McEniry M. Early-life conditions and older adult health in low- and middle-income countries: a review. J Dev Orig Health Dis 2013;4:10-29.
29 Wong R, Michaels-Obregon A, Palloni A. Cohort Profile: The Mexican Health and Aging Study (MHAS). Int J Epidemiol 2017;46:e2.

30 Verbrugge LM, Jette AM. The disablement process. Soc Sci Med 1994;38:1-14.

31 Katz S, Ford AB, Moskowitz RW, et al. Studies of illness in the aged. the index of adl: a standardized measure of biological and psychosocial function. JAMA 1963;185:914-9

32 Manton KG, Gu X, Lowrimore GR. Cohort Changes in Active Life Expectancy in the U.S. Elderly Population: Experience From the 1982-2004 National Long-Term Care Survey. J Gerontol B Psychol Sci Soc Sci 2008;63:S269-S281.

33 Manton KG, Land KC. Active life expectancy estimates for the U.S. elderly population: a multidimensional continuous-mixture model of functional change applied to completed cohorts, 1982-1996. Demography 2000;37:253-65.

34 Peterson B, Harrell FE. Partial Proportional Odds Models for Ordinal Response Variables. App/ Stat 1990;39:205-17.

35 Cai L, Hayward MD, Saito Y, et al. Estimation of multi-state life table functions and their variability from complex survey data using the SPACE Program. Demogr Res 2010;22:129-58

36 Liu Z, Han L, Feng Q, et al. Are China's oldest-old living longer with less disability? A longitudinal modeling analysis of birth cohorts born 10 years apart. BMC Med 2019;17:23.

37 Payne CF. Aging in the Americas: Disability-free Life Expectancy Among Adults Aged 65 and Older in the United States, Costa Rica, Mexico, and Puerto Rico. J Gerontol B Psychol Sci Soc Sci 2018;73:337-48.

38 Davison AC, Hinkley DV. Bootstrap methods and their application. Cambridge ; New York, NY, USA: Cambridge University Press, 1997: 582 p.

39 Dugoff EH, Schuler M, Stuart EA. Generalizing observational study results: applying propensity score methods to complex surveys. Health Serv Res 2014;49:284-303.

40 Torres JM, Wong R. Childhood poverty and depressive symptoms for older adults in Mexico: a life-course analysis. J Cross Cult Gerontol 2013;28:317-37.

41 Mejía Arango S, Wong R, Michaels-Obregón A. Normative and standardized data for cognitive measuresin the Mexican Health and Aging Study. Salud Publica Mex 2015;57:90-6

42 Knaul FM, González-Pier E, Gómez-Dantés O, et al. The quest for universal health coverage: achieving social protection for all in Mexico. The Lancet 2012:380:1259-79.

43 Parker SW, Saenz J, Wong R. Health Insurance and the Aging: Evidence From the Seguro Popular Program in Mexico. Demography 2018:55:361-86.

44 Robles G, Calderon G, Magaloni B. Las consecuencias económicas de la violencia del narcotráfico en México [Internet]. Inter-American Development Bank, 2013. Available: http://publications.iadb.org/handle/11319/4679 [Accessed 31 Jul 2018].

45 DeGraff DS, Wong R, Orozco-Rocha K. Dynamics of Economic Security among the Aging in Mexico: 2001-2012. Popul Res Policy Rev 2018;37:59-90.

46 Barquera S, Campos-Nonato I, Hernández-Barrera L. Prevalencia de obesidad en adultos mexicanos, ENSANUT 2012. Salud Pública de México 2013:55:151-60.

47 Beltrán-Sánchez H, Crimmins EM. Biological risk in the Mexican population at the turn of the 21st century. J Cross Cult Gerontol 2013:28:299-316.

48 Palloni A, Beltrán-Sánchez H. Latin American Mortality Database (LAMBdA. Madison: University of Wisconsin, 2014.

49 Vaupel JW, Manton KG, Stallard E. The impact of heterogeneity in individual frailty on the dynamics of mortality. Demography 1979;16:439-54.

50 Gill TM, Allore H, Hardy SE, et al. Estimates of Active and Disabled Life Expectancy Based on Different Assessment Intervals. J Gerontol A Biol Sci Med Sci 2005:60:1013-6.

51 Bardenheier BH, Lin J, Zhuo X, et al. Compression of disability between two birth cohorts of US adults with diabetes, 1992-2012: a prospective longitudinal analysis. Lancet Diabetes Endocrinol 2016;4:686-94. 